\title{
Intraoperative MRI detects a pattern of remnants?
}

\author{
Bernhard Meyer
}

Received: 1 December 2010 /Accepted: 1 December 2010/Published online: 14 January 2011

(C) Springer-Verlag 2011

If I read the first sentence of the introduction to this article [2], I can assure everyone that I fully agree. I am considered a neurosurgeon with a very clear attitude towards "radical removal" of low-grade gliomas. If I weigh the evidence, my conclusion is that complete removal of low-grade gliomas is a worthwhile undertaking.

I also agree that technical adjuncts, which help to make surgery safer and more complete, should be employed whenever possible.

It is neither new nor surprising that the resection of gliomas is often incomplete despite the opposite intention. We know that from postoperative imaging studies since the seminal article of Albert et al [1].

The authors confirm this long known fact by their intraoperative MRI studies. This is nice to know. No less, no more.

The message of this paper boils down to the simple statement that you should have a look under your spatula, a lip of brain or other hidden areas in your resection cavity before you close the dura to reduce the chance of incomplete removal.
Now I would not call it a major surprise to detect this "pattern". I even dare to say you would not need a million euro machine for its prediction. And you certainly do not need a "classification".

Sometimes it is just better to keep simple and obvious things the way they are.

Conflicts of interest None.

\section{References}

1. Albert FK, Forsting M, Sartor K, Adams HP, Kunze S (1994) Early postoperative magnetic resonance imaging after resection of malignant glioma: objective evaluation of residual tumor and its influence on regrowth and prognosis. Neurosurgery 34(1):45-60, discussion 60-1

2. Gerganov V, Samii A, Stieglitz L,Giordano M, Luedemann WO, Samii M, Fahlbusch (2010) Typical 3-D localization of tumor remnants of WHO grade II hemispheric gliomas-lessons learned from the use of intraoperative high-field MRI control. Acta Neurochirurgica (in press)
B. Meyer $(\square)$

Department of Neurosurgery, Klinikum rechts der Isar,

Technical University of Munich,

Ismaninger Str. 22,

81675 Munich, Germany

e-mail: Bernhard.meyer@1rz.tum.de 